\title{
Towards the revision of the EU biofuels directive what future for european biodiesel markets?
}

Raffaelo GAROFALO

EBB - European Biodiesel Board,

Boulevards Saint-Michel, 47,

1040 Bruxelles

Fax : 0032 (0)2 7377696

<ebb@ebb-eu.org>

\section{A Visionary policy}

The European Commission issued its first "Communication on alternative fuels for road transportation and on a set of measures to promote the use of biofuels" in November 2001 [1]. As from its beginnings the EU biofuels strategy was conceived as a visionary policy, based on the assumption that biofuels promotion was needed at least for three main reasons: contribute to the security and independence of energy supply, reduce GHG (Greenhouse emissions $\mathrm{Gaz}$ ) and $\mathrm{CO}_{2}$ emissions from the transport sector, create an additional outlet for EU agricultural production thus encouraging rural development.

Since then facts have confirmed that the EU biofuels strategy was indeed a visionary policy, conceived at an early stage to tackle problems whose solution has become more and more urgent across the last years.

\section{Contributing to the security and independence of energy supply}

In the last quarter of 2001, at the time of the Commission biofuels Communication proposal oil prices were at 19,41\$ per barrel (figure 1), i.e. at their lowest level in the last 6 years. Since then oil demand has grown steadily and oil prices have been multiplied by three reaching an average of $61,79 \$ / \mathrm{bbl}$ in the first quarter of 2006 (i.e. the highest level in the last 6 years). This consideration alone easily demonstrates not only that the objective of promoting biofuels is still valid, but that is today definitely even much more valid than what it was in 2001 . Although oil price growth already partially includes geo-strategic considerations, the deterioration of the geo-strategic situation in the Middle East and in other oil producing countries (Venezuela, Nigeria, etc.) has to be considered as a supplementary reason to conclude that the objective of promoting biofuels for security of supply is even much more valid than 6 years ago.
As far as diesel markets are concerned EU diesel demand increased dramatically in the last years leading to a substantial rise in EU diesel imports from third countries and more particularly from Russia. Observing the continuing dieselisation of EU cars and the increasing demand for diesel (from the US and world-wide), analysts predict a future diesel shortage threat for Europe that may face a shortfall of 50 million tonnes a year of diesel by 2015 under current investment schemes [2] further confirming the validity of promoting biofuels and even the specific urgent necessity, for Europe, to promote the available diesel substitutes and notably biodiesel.

\section{Reducing $\mathrm{CHG}$ and $\mathrm{CO}_{2}$ emissions from the transport sector}

Under the Kyoto Protocol, the EU has committed to reduce its overall emissions of greenhouse gases by $8 \%$ compared to 1990 levels.
While GHG emission from most sectors are decreasing or are at least stable, $\mathrm{CO}_{2}$ emissions from transport (which accounts for $21 \%$ of the overall GHG emissions) did not stop growing over last years. As confirmed in a recent Commission report: "The transport sector shows a continuous increase in $\mathrm{CO}_{2}$ throughout the period for which data are available (since 1990) and is still growing (24\% above the 1990 level in 2003 for the EU-15)" [3]. The EU transport sector is in fact the only sector which, beside being over $95 \%$ dependent on imports is depending for more than $98 \%$ on fossil energy.

Looking to the future, $\mathrm{CO}_{2}$ emissions from transport are expected to keep rising, contrary to agreed objectives to reduce them. This makes it more difficult for the Union to respond to the challenge of climate change and to meet its commitments under the Kyoto Protocol. Moreover, the commitments made under the Kyoto Protocol must be regarded as a first step.

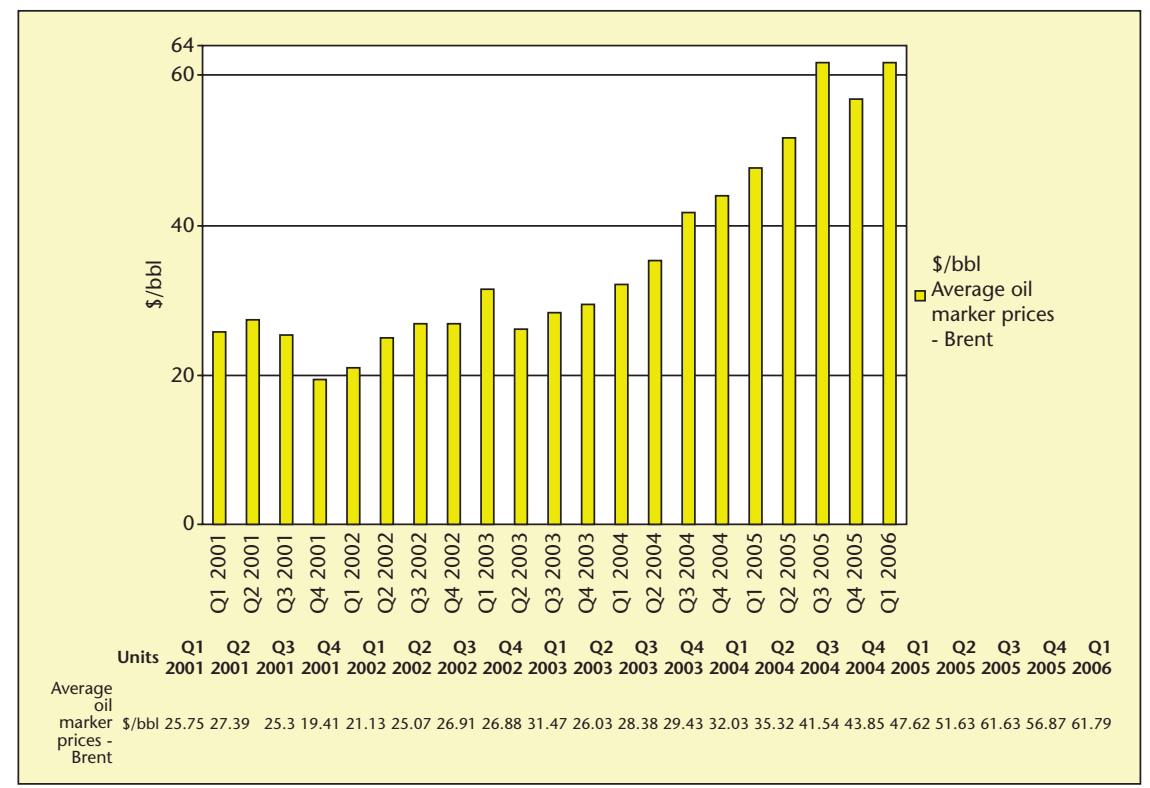

Figure 1. BP quarterly data 2001-06, average oil market price - Brent. Source: BP. 


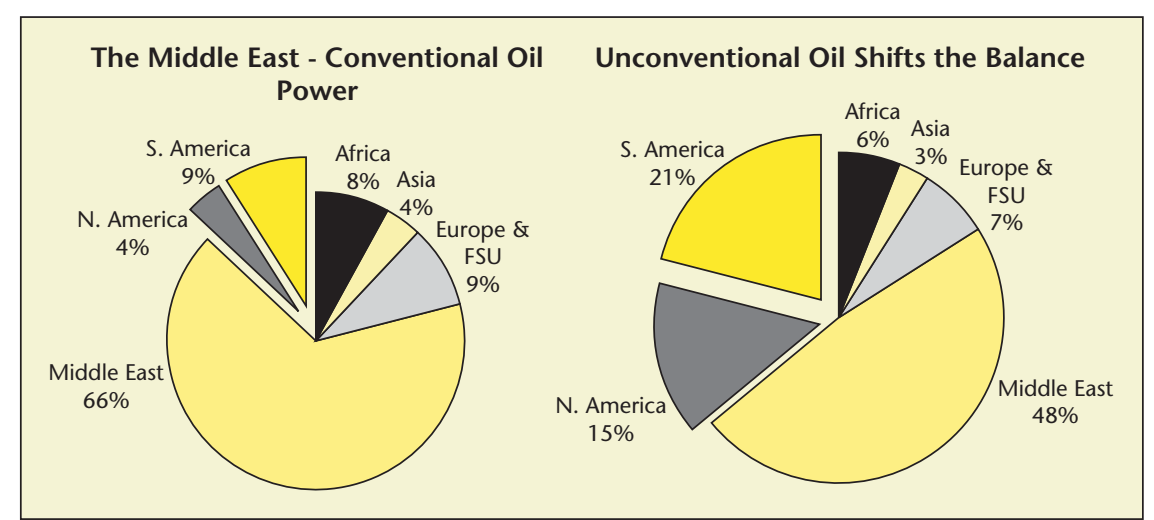

Figure 2. Effect of Canadian and Venezuelan unconventional oil on world oil reserve balance. Source EIA.

Knowing that biofuels represent the only solution available in order to reduce $\mathrm{GHG}$ and $\mathrm{CO}_{2}$ emission from the transport sector it is clear that last years' developments have confirmed the validity of the objective of promoting biofuels as an answer to transport impact on climate change, even providing a stronger case for strengthening the EU biofuels policy and for defining higher biofuels objectives for the medium and longer term.

Also, in terms of global $\mathrm{CO}_{2}$ emissions the marginal contribution from biofuels to reduce future oil demand is likely to have an exponential positive effect on $\mathrm{CO}_{2}$ emission reduction. The future marginal oil demand (which will be reduced by the future marginal increased biofuels use), in fact, will be manly satisfied by unconventional oil extraction (both for reasons of price and of security of supply - most of unconventional oil reserves being in North and Latin America) (figure 2). Now, $\mathrm{CO}_{2}$ emissions from unconventional oil extraction are much worse (until six times worse for Canadian tar sands [4] - i.e. the main source) than $\mathrm{CO}_{2}$ emissions from today's conventional oil extraction (figure 3, table 1). Clearly a global marginal contribution from biofuels to reduce marginal oil demand from unconventional extraction will have a much larger impact than the 60 to $80 \%$ GHG reduction mentioned in most reliable LCAs comparing conventional fossil fuels and biofuels [5] (more particularly biodiesel).

\section{Creating an additional outlet for EU agricultural production, stimulating rural development}

Rural development is an increasingly important part of the Common Agriculture Policy. An essential facet of the European agricultural model, which aims to put in place a consistent and lasting framework for guaranteeing the future of the rural community, is the creation of employment. Increased production of raw materials for biofuels will continue contributing to the multifunctionality of agriculture and pro- vide a stimulus to the rural economy through the creation of new sources of income and employment. As an example a German study [6] performed by the IFO Institute showed the rate of economic impact to be 16 employees per ktoe/year. The Spanish national plan for biofuels puts the figure at 26 employees per ktoe/year of biofuels produced (source: IDAE). Furthermore after last CAP reform and decoupling, and after the recent sugar reform biofuels are likely to play an even more important

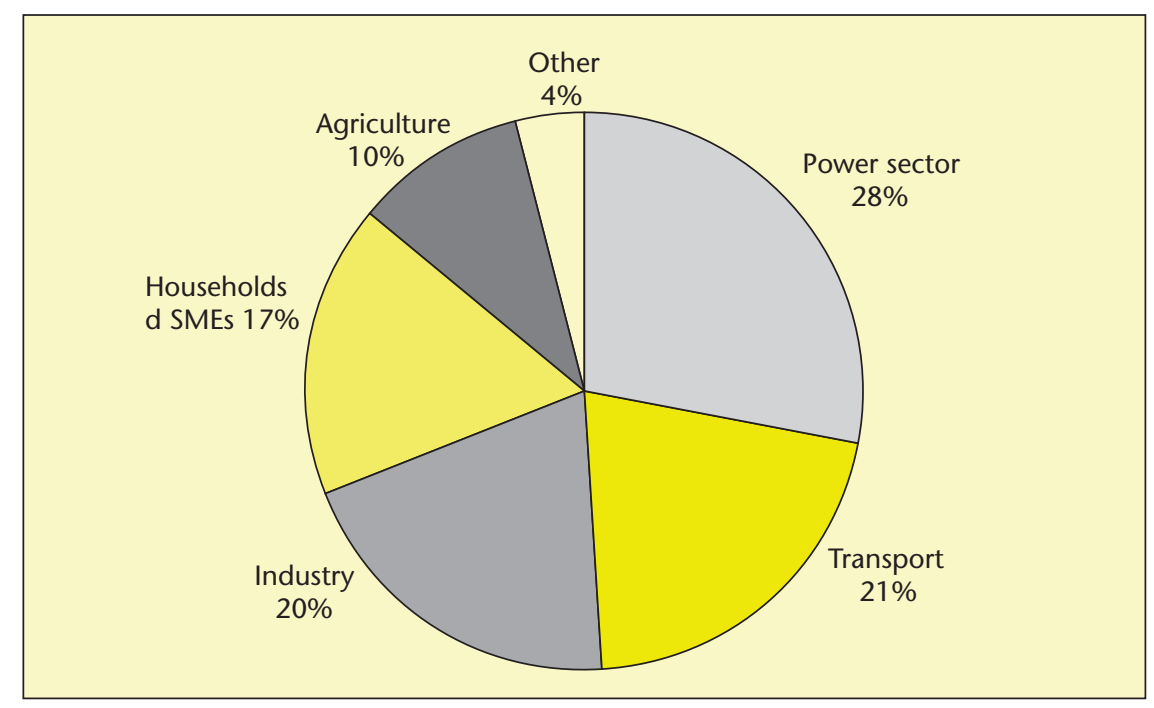

Figure 3. Sources of EU greenhouse gas emissions. Source: EEA.

Table 1. GHG emissions by sector for 1990 and 2003 (in million tonnes CO2 equivalent emissions) for EU-15. Source: $E E A$.

\begin{tabular}{|lccc|}
\hline Source category & $\mathbf{2 0 0 3}$ & $\begin{array}{c}\text { Share of total emission } \\
\text { in 2003 (\%) }\end{array}$ & $\begin{array}{c}\text { Change } \\
\mathbf{1 9 9 0 - 2 0 0 3}(\%)\end{array}$ \\
\hline Energy excl.transport & 2521 & 61 & -3 \\
Transport & 872 & 21 & +24 \\
Industrial processes & 265 & 6 & -19 \\
Agriculture & 414 & 10 & -10 \\
Waste & 97 & 2 & -32 \\
\hline
\end{tabular}

role as alternative outlets for EU agriculture. Biofuels development is also a key tool for the phase up of agriculture in the new EU Member States and may play a key role in new accession countries where the agricultural activity per capita was at least double than in the old EU-15. There is therefore further potential for sustainable farming of biofuels in these countries. Biofuel production could further contribute to agricultural diversification, help to meet the environmental challenge and form part of job creation policy. In this sense, with respect to agriculture, the objective of promoting biofuels in the EU appears to be still as valid as it was in 2001 for the EU-15, highlighting a clear further need in terms of new jobs and diversification of the outlet for the new Member States and for the next accession countries (Romania, Bulgaria and Croatia).

\section{Will the $5.75 \%$ target be achieved in 2010?}

Although the global EU biofuels target is rather unlikely to be attained, the situation will be very likely to vary from one Member State to the other as well as depending on which biofuel is considered. 
The different policies adopted in Member States, the inconsistency of some of them as well as the lack of a real political will in some EU countries constitute the main reason for which a 5,75\% biofuels market share appears as quite unlikely to be attained on time as a whole. Already the 2\% global biofuels target for 2005 set by EC Directive 2003/30 has not yet been met.

However some countries such as France and Germany, having already reached the $2 \%$ target appear to be in the right path to attain the $5,75 \%$, eventually even with some advance with respect to the deadline of end 2010 .

As far as the differences among biofuels are concerned it needs to be underlined that, biodiesel makes up today around $80 \%$ of EU biofuels production [7] - bioethanol being the other major biofuel. Although as specified above the $2 \%$ target was not met in 2005 , still considering only EU diesel markets, biodiesel production got closer than expected to the $2 \%$ target, representing approximately a 1,5\% market share of the conventional EU diesel market in terms of energy content at the end of 2005, when the overall biodiesel production in EU-25 increased from 1,9 million in 2004 tonnes to nearly 3,2 million tonnes in 2005 (with an unprecedented 65\% yearly growth for EU biodiesel production) (table 2). Already in 2004, 2003 and 2002 biodiesel production rose by $30-35 \%$ when compared to the previous year, marking a continued expansion of the European biodiesel sector.

Although most biodiesel production can be attributed to EU-15 Member States, the number of EU countries with a biodiesel industry has nearly doubled in 2005. Today, 20 countries are producing biodiesel on an industrial scale, up from 11 countries that produced biodiesel last year.

On the other hand and considering that the $5,75 \%$ target would require approximately between 12 and 18 million tonnes of biodiesel (depending on the biodiesel/other biofuels share that will subsist in the markets) the capacity of production of the EU biodiesel industry should be ready to attain this target on time. Already this year (situation on 1/07/2006) EU biodiesel production capacities are attaining 6 million tonnes (table 3) per year and should be well beyond 8 million tonnes at the end of 2007. The European biodiesel industry is therefore ready to reach the EU biofuels targets; still more important efforts should be done in order to support to the production of biodiesel raw materials as well as in order to stimulate biofuels demand from the markets.

The important growth in the EU biodiesel industry both in terms of production and capacities, as well as the increasing number of new plant projects prove anyhow that,
Table 2. EU 2005 and 2006 biodiesel capacity estimates. Calculation based on 330 working days per year, per plant (situation at 01/07/2005 and at 01/07/2006). Source: EBB.

\begin{tabular}{|lcc|}
\hline COUNTRY & $\begin{array}{c}\mathbf{2 0 0 5} \\
\text { Capacity }\end{array}$ & $\begin{array}{c}\mathbf{2 0 0 6} \\
\text { Capacity }\end{array}$ \\
\hline Austria & 125 & 134 \\
Belgium & 55 & 85 \\
Cyprus & 2 & 2 \\
Czech Rep. & 188 & 203 \\
Denmark & 81 & 81 \\
Estonia & 10 & 20 \\
France & 532 & 775 \\
Germany & 1.903 & 2.681 \\
Greece & 35 & 75 \\
Hungary & 0 & 12 \\
Ireland & 0 & 0 \\
Italy & 827 & 857 \\
Latvia & 5 & 8 \\
Lithuania & 10 & 10 \\
Luxemburg & 0 & 0 \\
Malta & 2 & 3 \\
Netherlands & 12 & 0 \\
Poland & 129 & 52 \\
Portugal & 100 & 150 \\
Slovakia & 6.228 & 146 \\
Slovenia & 8.069 \\
Spain & 17 & 17 \\
Sweden & 100 & 224 \\
UK & 12 & 59 \\
\hline TOTAL & 0 & \\
\hline
\end{tabular}

although the targets were not attained and will most probably be not attained in number of countries, their value went far beyond arithmetic. This confirms that the EU Directive has established the frame for a long term biofuels development in Europe. This Directive needs now to be revised and adapted in order to ameliorate and increase its action.

Certainly it would still be possible to attain the $5,75 \%$ target but only through a necessary re-orientation, harmonisation and strengthening of the existing $\mathrm{EU}$ and national policies on biofuels.

\section{Main factors favouring the development of biofuel use in the EU}

EU legislation has acted as a catalyst favouring the development of biofuels use in the EU, often resulting in the approval of national legislations (tax exemption and/or obligations). Although some Member States have not defined appropriate national biofuels policies, the EU legislation has had the merit to place the issue of biofuels at the centre of the political
Table 3. EU 2004 and 2005 biodiesel production estimates. Subject to $a+/-5 \%$ margin of error. Source: $E B B$.

\begin{tabular}{|lcc|}
\hline COUNTRY & $\begin{array}{c}\mathbf{2 0 0 4} \\
\text { Production }\end{array}$ & $\begin{array}{c}\mathbf{2 0 0 5} \\
\text { Production }\end{array}$ \\
\hline Germany & 1.035 & 1.669 \\
France & 348 & 492 \\
Italy & 320 & 396 \\
Czech Rep. & 60 & 133 \\
Poland & 0 & 100 \\
Austria & 57 & 85 \\
Slovakia & 15 & 78 \\
Spain & 13 & 73 \\
Denmark & 70 & 71 \\
UK & 9 & 51 \\
Slovenia & 0 & 8 \\
Estonia & 0 & 7 \\
Lithuania & 5 & 7 \\
Latvia & 0 & 5 \\
Greece & 0 & 3 \\
Malta & 0 & 2 \\
Belgium & 0 & 1 \\
Cyprus & 0 & 1 \\
Portugal & 0 & 1 \\
Sweden & 1 & 1 \\
\hline TOTAL & $1.933,00$ & $3.184,00$ \\
\hline
\end{tabular}

debate in all the Member States creating momentum for biofuels. In this sense it can be considered that the EU biofuels legislation has been, together with the sharp increase in oil prices, the main factor favouring the development of biofuels in the EU. The need to find additional outlets for the EU agriculture has also been playing some role especially at a very early stage in the late ' 90 s.

On the technical side the possibility of blending $5 \%$ of FAME in normal EN590 diesel has constituted a crucial asset for simplifying and accelerating the development of the European biodiesel market, although today the $5 \%$ ceiling appears to be already by far too low.

Finally it should not be neglected the importance that issues like the global warming and the abatement of pollution in the cities have in the European public opinion. This factor may represent a strong asset for biofuels although it has not been appropriately exploited until now.

\section{Main obstacles for the development of biofuels in Europe}

On the other hand the main obstacles for the development of biofuels are:

- The heterogeneity of national legislative systems and detaxation levels for biofuels. It consti- 
tutes today one of the main obstacles. Such heterogeneity leads to the absence of a real $E U$ Internal Market for biofuels cancelling the enormous benefits that would be related to free exchange. A more voluntary policy at EU level with lesser room left for subsidiarity would probably be needed in order to build up a real EU market for biofuels.

- The fact that only 5\% biodiesel (FAME) can today be blended in conventional diesel clearly constitute a major obstacle in order to guarantee a further development of biodiesel especially in those Member States (e.g. Germany or France) which have taken a lead in the production and the use of biofuels and biodiesel and are ready to go further. A $5 \%$ ceiling in volume when the target for 2010 is $5,75 \%$ in energy content (i.e. more or less $6,5 \%$ in volume - only accounting biodiesel) represents a barrier that will need to be removed as soon as possible. Furthermore it needs to be considered that for logistical reasons and in order to keep a good level of elasticity in the marketing of biodiesel and biofuels, not all of the refineries and fuels distributors should be required ${ }^{1}$ - regardless where their location is when compared to a biofuels plant - to blend a given amount of biodiesel. The 10\% level becomes an extremely urgent need in order to provide an appropriate larger room for FAME blending in those refineries situated closer to esterification or biofuels production plants. The willingness to amend and timescales involved in amending the standard specifications for diesel and gasoline for inclusion of biofuels in excess of $5 \%$ by volume is today a major barrier to achieving the target.

- Paradoxically an excessive enthusiasm for biofuels can also be considered as an obstacle since it has been leading sometimes to short term considerations, with low quality biofuels production "at the farm" or to not well reasoned attempts to use straight vegetable oils in conventional car engines (thus damaging the injection system and other part of the diesel engine). EBB urges the Commission to put an end to such practices, which may risk, in the long term, to make biofuels a victim of their own success.

- As far as pure FAME or high biodiesel blends are concerned the fact that vehicle and engine warranties are often provided in an inconsistent way across the different EU countries (a same lorry with a same engine may have a warranty for $100 \%$ biodiesel use in Germany, without having a B30 warranty in France) represents an obstacle. This partially explains why the use of B25 or B30 blends in captive fleets has never taken off in Europe. EBB encourages the European Commission to try to tackle this problem

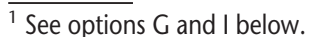

also underlining that the existence and allowance of warranties should follow technical considerations without being based only on the strategic interests of car manufacturers. An official register kept by EU authorities, on the basis of which if a warranty is given for biodiesel use for an engine in a Member State it should then automatically be given for the same engine in all the EU-25 may eventually represent a solution to such a problem.

- Another obstacle is represented by the fact that the use of some alternative raw materials for biodiesel production, e.g. used (frying) oils and/or different kind of animal fats that would potentially represent an important source supply, but cannot be fully exploited because of the legal definition applying at Member State level to one or the other group of waste. It would be important to clarify the current confusion existing in the implementation of the EU definition of biomass and waste, in a way that the potential of these raw materials (particularly interesting in terms of price and of $\mathrm{GHG}$ savings) can be used at EU level. On the other hand, talking about future biofuels technologies it would be important to specify that only those processing biomass (and NOT BTL from plastics, coal or non-biomass waste) are entitled to be considered biofuels.

- Finally it needs to be underlined that, in spite of the general environmental image that some oil companies ${ }^{2}$ seem to be willing to create around them, in reality there has never been a real attempt from oil majors to campaign about the presence of up to $5 \%$ biodiesel in their diesel. Probably they have always feared that with such campaign they would have created a consumer demand for biofuels and biodiesel, thus guaranteeing biofuels a permanent market. It would be important that EU authorities could impose the creation of such a direct relationship between biofuels producers and consumers in order to strengthen the future development of the sector.

\section{Implementation of Directive 2003/30 what has been achieved and what still needs to be done?}

Until now the EU policy in favour of biofuels met a partial success by setting ambitious targets and by paving the way to biofuels legislation in many Member States. Still, the practical implementation of the Directive in some countries represents today a real failure of the sys-

${ }^{2}$ As an example the acronym BP which is today advertised as "Beyond Petroleum". tem preventing the establishment of a real Internal EU Market for biofuels. EBB has urged the EC Commission to consider these aspects in its implementation report to be issue before the end of 2006 and propose some modification to Directive $2003 / 30$ in order to ameliorate the impact of the legislation.

\section{Biofuels obligations need to co-exist with national excise exemptions}

Ideally a revision of Directive 2003/30 should lead to the establishment of national obligatory system (applying possibly at Member State level to mineral oil distributors), still keeping the possibility of reducing or exempting biofuels from the excise duty on mineral oils applied at national level. In other words this means that EBB would like to suggest to the Commission to implement a system of "policy mix" using contemporarily the two tools of obligations and tax reduction/exemptions. The concept of a biofuels obligation entails three main advantages when compared to detaxation alone, since:

- it transfers to the final fuel consumer the extra costs linked to biofuels production fully implementing the "polluter pays principle" (the consumer using more fuel contributing more than the others to the support of biofuels);

- the extra costs remain rather unnoticeable for the final consumer: Commission DG TAXUD calculated [8] that for a $5 \%$ blend it would be necessary to increase only by 1 or 2 Euro cents the final price at the pump - which by far lower than the price fluctuation occurring in the same week or the differential often existing between two different pumping stations; - it may provide a good basis for the beginning of an EU harmonisation, this much more easily than under the detaxation tool, taxation policies being condemned to remain merely national policies even in the long term;

- last but not least an important reserve should be highlighted: EBB believes that it would be important to recommend to member States to put a ceiling (or a buy-out price) to national obligation in order to avoid the fixation of anti-economical price levels that, well beyond the aim of promoting biofuels may have negative consequences for the EU economy and more particularly for the EU food sector. Still such buy-out price should be maintained high enough in order to guarantee a real incentive to blend biodiesel and biofuels rather than pay an eventual fine.

EBB has urged the Commission to consider that it will be crucial to maintain, in parallel to an European or national obligation, the possibility for Member States to exempt or reduce tax exemption for biofuels and this under the 
present multi-annual system (6 years), i.e. without being obliged to require such an authorisation every year to the Council of the EU voting at unanimity. The detaxation tool in fact will be needed for:

- maintaining the practical possibility of promoting a market for pure biodiesel and for high blends of biodiesel in captive fleets (with an obligation it is impossible to report all of the extra-costs of pure biofuels to the final consumer still keeping a competitive price at the pump). This would mean to maintain and promote those markets that make biofuels and biodiesel more visible to the final consumer; - creating a system of "policy mix" where the burden of the extra cost related to biofuels production is beard not only by the final consumer but also, in part, by the national budget, thus distributing the charges and making such burden less noticeable for both the consumer and the national budgets.

\section{Communication campaign}

Last but not least EBB believes that mineral oil distributors should be encouraged to campaign on biofuels and create a demand for fuels blended with biofuels, still avoiding to create complicate rigid systems of tractability and labelling such as the one that would be required under this option, that, as such (i.e. implying a precise labelling of the percentages of biofuels contained), should be discarded. However it might be interesting to encourage fuel distributors and mineral oil companies - on a voluntary basis - to organise marketing campaigns marketing their products in blends with biodiesel as a "higher profile" product, thus giving biofuels a boost and encouraging consumer demand.

\section{Biodiesel in public fleets}

It would be probably worth considering to establish some kind of obligation or public procurement at EU and/or national level for public or local transport captive fleets to use high blend or pure biofuels. This would have a relatively marginal impact on the quantities of biofuels sold in the market but would end up creating by itself an efficient campaign in favour of biofuels in all the EU countries. Biofuels market are being mainly developed on the basis of low blends of biofuels (for biodiesel blends of up to $5 \%$ ). Such a system is a successful one since it implies all the advantage related to simplicity and to easy blending by mineral oil distributors. Still if this marketing system alone was retained the communication deficit on biofuels which already exists may risk to worsen. An obligation for public fleets to use pure or high level blends of biodiesel would create an easily identifiable use for biodiesel (a sort of flag for the product - as already observed in France, Italy, Germany and Austria) and may be the right answer to the present deficit of visibility.

Another important point in the frame of the revision of the Directive would be to make sure that no labelling requirement should apply to biofuels (or more specifically to biodiesel) blends below $10 \%$. Today a $5 \%$ principle applies for labelling. It should be adapted taking into account the need to normalise the use of FAME blends up to $10 \%$ and in the light of the undergoing revision of the EN590 standard on diesel, for which the Commission has recently sent a mandate to the CEN.

\section{Biofuels sustainability and certification}

The environmental sustainability of the agricultural or forestry raw materials with which biofuels are or will be produced is clearly a fundamental aspect of their future development. Obviously the issue needs to be tackled in an appropriate perspective and a distinction needs to be applied between the raw materials produced within the EU and the raw materials or the biofuels imported from third countries. This distinction is quite fundamental also in the case of biodiesel since it is worth mentioning that more than $90 \%$ of the biodiesel produced in Europe today is originated from EU raw materials and that such a situation is expected to be modified only but marginally within the next 5 years EU biodiesel raw materials being expected to cover at least 80 to $85 \%$ of the biodiesel industry demand of supply.

For EU produced raw materials EBB considers that the current cross-compliance rules (on the negative side) and the agri-environmental measures of the CAP (on the positive side) applying to food and non-food productions have to be considered as sufficient and there would be no necessity to strengthen them.

As far as imported raw materials (or imported finished products) are concerned the EBB favours the establishment of an eventual certification system aiming to avoid the nonsustainable use of limited natural resources (notably of the rain forest) provided that such a system:

- is conceived as an efficient and nonbureaucratic system, whose cost impact on the final product is as negligible as possible, still maintaining the necessary efficiency, in order to avoid that it may represent a non-tariff obstacle to imports or that it may contradict the main aim of biofuels promotion policy which is today to reduce the final cost of the biofuels (and for biodiesel the final cost depends approximately on $80 \%$ on the cost of the raw materials);
- is conceived as a non-discriminatory system, applying to any kind of agricultural or forestry raw material regardless what its final use is. A certification system only targeting biofuels in fact would not only create a discrimination but also it would fall short in preventing the rain forest to be depleted. As an example if only palm oil originated biodiesel and not palm oil originated margarine were to be submitted to a system of certification probably all of the biodiesel would be produced from certified "clean" areas while the forest would continue to be depleted in the same proportion as before to produce oil in order to satisfy the remaining demand for margarine;

- is implemented within a long term frame, the industry and market operators needing at least a period of 5-10 years to adapt their production, logistic and marketing to an eventual new sustainability certification.

\section{A multilateral and horizontal approach to biofuels sustainability}

As far as imported raw material are concerned the existing pattern of the Round Table on Sustainable Palm Oil, which is already in an advanced stage of conception and the Round Table on Sustainable Soybean Oil, which is now still at and earlier stage of elaboration should both be used as a basis for any eventual EU system.

Only a multilateral approach such as the one of these two round tables, in fact, can guarantee that all of the palm oil, soybean oil or (mutatis mutandis any other imported biofuel raw material) is submitted to the same certification conditions regardless what the final country of destination is and regardless what its final use is. There would be little use, in fact, in establishing a certification system for the raw material used for producing biodiesel for the EU market only, while the rest of the word would continue to use the same raw material for biofuels or food use still depleting the rain forest or the environment.

In this sense EBB has recommended to the $\mathrm{EC}$ Commission to take an initiative vis-à-vis UN and international organisations to promote the establishment of a multilateral horizontal sustainability system applying to the use of all agricultural or forestry product.

As far as the eventual details of such a system should be defined EBB relies on the detailed rules agreed by the stakeholders (including green NGOs) involved in the Round Table on Sustainable Palm Oil and further relies on the position expressed at EU level by the representatives of the $\mathrm{EU}$ vegetable oil producers and seed crusher association (FEDIOL). 


\section{Is a certification system for biofuels needed? What would be its consequences?}

In the light of previous consideration on sustainability, the issue of biofuels certificate needs as well to be analysed in the frame of the present and future situation of biofuels prices (especially when compared with conventional fuels) together with the direct and indirect consequences that a certification system would imply. In fact, before any conclusion can be drawn, the following point should be considered:

- the main challenge that biofuels will have to tackle in the next years will be to reduce the price gap between biofuels and conventional fuels;

- biodiesel alone (as an example) is produced sofar in 136 different production sites (only accounting the European ones) each using every day different sorts of raw materials (ranging from rape oil to recycled fats, animal fats, soybean oils, etc.);

- all these raw materials have each a very different $\mathrm{CO}_{2}$ profile - depending on their origin (soybean oil from Italian grown soy does not have the same $\mathrm{CO}_{2}$ profile of soybean grown in Brazil - among other due to different transport distances - the same applying to rape grown in Germany, Canada or Australia) and depending on the pesticides and fertilisers that have been eventually used (degree of intensity of the culture, etc.);

- the same raw materials have very different implications in terms of security of supply, depending again on their origin and on their global availability;

- a wider system of certificates indicating the greenhouse gas and the contribute of the security of supply would necessarily need to be extremely complicated in order to take in good account the differences existing among different raw materials and from a plant and another due to the differences of processing, transport, storage, etc.;

- if applied to different kinds of biofuels a certification system should apply also to different kind of oils depending on their origin and on the way in which they have been extracted - if there should be a ranking among biofuels in fact, logically a ranking among different fuels should as well exist with respect to the $\mathrm{CO}_{2}$ and security of supply of one or the other mineral fuel.

Starting from these consideration the European biodiesel industry believes today that such a certification system would risk:

- either being too complicated thus creating a burdensome bureaucratic system leading to an unjustified additional cost burden for biofuels which would directly contradict the aim itself of the EU strategy on biofuels to reduce the long term price gap with conventional fuels;

- or, if the necessity of simplifying was taken into duly account, to be ineffective and therefore useless or even discriminatory against those raw materials or those producers whose contribution to the security of energy supply or $\mathrm{CO}_{2}$ reduction should be accounted more than for others.

Considering as well that the $\mathrm{CO}_{2}$ and the security of supply impact of biofuels has been widely demonstrated as extremely positive when compared to the one of fossil fuels (with a range of 65 to $80 \%$ reduction in $\mathrm{CO}_{2}$ emission - still without taking into account unconventional oil extraction), EBB would like to convince Eu authorities to rely on the fundamental assumption that given that the objective of promoting biofuels is today still valid and by far much more urgent than it was even 5 years $\mathrm{ago}^{3}$, a strategic decision to strengthen the EU biofuels policy should be given strong support avoiding any hesitation and any certification that may hamper the final impact of the policy itself.

Furthermore the eventual definition of a certification system obeying to the theoretical idea (very difficult to implement) of distinguishing "the bad biofuels from the good ones", it is important to comment that such a concept would create a long list of problems related to: - the reference studies upon which the different biofuels and biofuels raw materials should be evaluated in terms of their $\mathrm{CO}_{2}$ performances. The JRC study on "Well to Wheel" is sometimes evoked as an indisputable reference, but in reality is one study among at least 200 other researches realised by high level universities and research studies world-wide. EBB and other EU biofuels Industry Associations have repeatedly tried to contribute and to participate to the work and the update of the "Well to Wheel study" that the JRC has realised with the mineral oil industry (Concawe) and the EU car manufacturers industry (EUCAR). This study, in which no stakeholders from the biofuels industry or from the agricultural sector have ever been directly involved, with a real say about the conclusions, should be considered as one-sided and should not be used as a neutral reference. Interestingly the JRC "Well to Wheel" digs in a large number of possible raw materials and processing for producing biofuels, while on the fossil fuel side it is based on the surprisingly simple assumption that there is only one kind of fossil fuel and no differences among the $\mathrm{CO}^{2}$ impact of, for instance different oils extracted and processed in different parts of the globe.

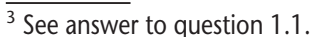

Given that this is clearly not the case and also considering that biofuels will substitute the marginal part of oil extraction (i.e. the last barrel) which is incontestably the most expensive and the most difficult to extract, EBB is raising the interest of European and National public authorities on the important need to realise a comparison study between the various biofuels and the various kinds of conventional fuels (diesels and gasolines) taking into account all kind of oil sources and more particularly the marginal part of oil extraction that the marginal biofuels market share will substitute. More particularly it would be appropriate to include in such a study the impact that the development of biofuels (in Europe and worldwide) will have in delaying or reducing the extraction of Canadian tar sands or Venezuelan non conventional oils.

- the reference studies upon which the different biofuels and biofuels raw materials should be evaluated in terms of their security of supply performances. (There is little or no study comparing the security of supply performances of one or the other biofuel): a political decision should rather be taken starting from the general observation that the EU experiences every year increasing gasoline surpluses and diesel deficits;

- the reason for which although biofuels are promoted for three reasons their positive impact on GHG, security of supply and agriculture the respective contribution to agriculture and rural employment of each biofuels should not taken into account for distinguishing the "bad from the good" performing biofuels. Clearly this would constitute a logical inconsistency with the aim and the basic scopes of the Directive. EBB is convinced that if the aim of any certification would be to distinguish and rank among the "good" and the "bad" biofuels this should absolutely not be done, for obvious reasons of logical consistence only on the basis of one or two of the objectives of the biofuels policy but on the basis of all of the 3: i.e. security of supply, GHG emission reduction and also agriculture and rural development.

As a conclusion it would be appropriate to focus EU legislation efforts on an efficient and visionary policy in favour of all biofuels - since we will need all of them to tackle the problems of GHG emission, energy supply and rural development.

Should a certification system be envisaged anyhow the European Biodiesel industry will insists that:

- its adoption should be postponed until the moment when an impartial Commission study comparing biofuels with different kind of fuels including oil from non-conventional extraction will be realized; 


\section{International biodiesel markets and fair trade: the two threats of subsidised "B99" "blends" from the US and of Argentinean differential export taxes (DETs)}

Representing more than $80 \%$ of global production he EU is by far the world leading biodiesel industry. This is mainly due to the strong demand existing for biodiesel in the European market.

Biodiesel is becoming a world-wide reality and new industries are emerging in many other countries, including the US, Brazil, Argentina, Canada, Malaysia, Indonesia, Australia, Korea, etc. As a consequence international exchanges have started and they will probably lead to the creation of an international biodiesel market. As from the beginning it would be important that international biodiesel exchanges follow WTO rules and are based on a level playing field avoiding any kind of unfair trade practice. Unfortunately however two major threats exist today for fair trade of biodiesel. Both these threats are originated from national support schemes applying to export of biodiesel or of biodiesel blends.

At present, in the frame of Federal measures adopted last year to promote biodiesel, US biodiesel producers are eligible for a subsidy of 1 US cent for every gallon of biodiesel blended with mineral diesel. This means that, in practice, biodiesel can be subsidised up to 250 $260 \$$ per cubic meter only by adding a "drop" of mineral diesel to biodiesel. A "B99" blend (if it can still be considered a "blend...") in fact gets the maximum subsidy for blending and is then ready to be exported to Europe in order to fully benefit from the European subsidy schemes. Although the US subsidy scheme was not conceived with such a purpose, in practice an increasing number of imports from the US being realised in such a way. This system clearly represents an unfair trade measure that urgently needs to be reviewed and eliminated at least in its unfair trade aspects - by the US government. This also in the light of the fact that triangular trade is starting with biodiesel producers or traders from third countries (Malaysia, Brazil, etc.) shipping biodiesel in US harbours to be "blended" with a $1 \%$ (but even a $0,001 \%$ would be enough) for exporting to Europe afterwards. Such a system therefore represents not only a serious threat to fair trade, but also a net loss for the US government in terms of support given to its national biodiesel industry.

Argentinean differential export taxes (DETS) are based on a different mechanism, but still represent a strong and unfair export subsidy favouring Argentinean biodiesel producers - and mainly potential producers, since the Argentinean biodiesel industry is still at an infant stage. Oilseeds produced in Argentina are subject to a
$23 \%$ export tax, vegetable oils to a $20 \%$ export tax while biodiesel produced in Argentina issubject to a $5 \%$ export tax, which is even reduced to $0 \%$ in case biodiesel is blended with diesel (making it possible in theory to earn more or less an additional 5\% - on top of the $15 \%$ discount - with a sort of "Argentinean B99" via adding a "drop" of diesel in biodiesel). A $15 \%$ to $20 \%$ incentive given to the local Argentinean biodiesel industry for processing vegetable oils in FAME, at the only condition of exporting them is clearly a market-distortive interference in international biodiesel trade that should be urgently solved. The fact that there is little biodiesel production today in Argentina should not be used as a pretext for inaction, on the contrary it would be important, in a fair environment, that investment is made based on market-distortive measures that cannot be accepted by the international community.

The EBB has recently informed EC Commission DG TRADE about the threat coming from such market-distortive measures in force in the US and in Argentina and about their potential effects. Additional activities of industry representatives and official reactions from public authorities on these two items are expected in the forthcoming weeks.
- the system should be as simple as possible and based on an evaluation on the impact of each biofuels on all of the three issues for which biofuels are promoted (i.e. not only $\mathrm{CO}^{2}$ but also security of supply and EU rural development unless the objectives of the Directive are going to be changed...);

- an eventual reward given to biofuels could only be given to the best performing biofuels with respect to the three Directive targets as detailed above;

- to be consistent with the scope of the Directive the system should contribute to decrease biofuels price or should leave it unchanged;

- its adoption and its definition should be realised along a time frame of 7-10 years in a way to enable the industry and the other stakeholders involved to adapt their investments and their behaviour to the new reality;

- if adopted it should apply not only to biofuels but also to every kind of fuel (renewable or conventional), thus enabling a ranking penali- sation of the worst performing conventional fuels in terms of $\mathrm{CO}_{2}$ emissions and security of supply.

\section{Biodiesel and bioethanol versus future biofuels technologies?}

Future biofuels technologies constitute today a promising path for research. In the long to medium term there are good possibilities to start with pilot projects (as it is already the case for the Choren BTL project or for the new hydrogenation technology developed by Neste Oil and Total) and end up to large scale production. Future biofuels technologies should normally entail advantages in terms of flexibility in the use of raw materials and are reported to be more $\mathrm{CO}_{2}$ efficient at least in laboratory test or pilot project plants (but there are many exceptions as well). On the other hand they require much higher investment costs and are based on much more energy demanding processes. Also, particularly referring to BTL production, questions are raised about the cost and GHG efficiency of, among others, transporting impressive volumes of very low specific weight raw materials as straw towards very large scale economy processing plants. On theoretical assumptions of feasibility plans such straw are considered as "zero" value purchase raw materials, but it is clear that, if the technology would be employed on a large scale straws would become an economic good with much higher prices. Also if straws are not kept on the field it implies a further environment and economic cost for the lack of their natural contribute to fertilisation, since chemical fertilisers would be employed to balance the absence of straws on the fields.

As highlighted before the European Biodiesel industry considers that a biofuels certification system would involve number of unsuitable 
consequences. If anyhow such a system was to be adopted future biofuels technologies should be evaluated as the other available biofuels with respect to all of the three Directive targets. Eventual reward systems should therefore reflect the eventual (effectively proven) advantages or disadvantages that they entail according to the Directives' objectives. Any other kind of stronger incentive to favour them when compared to other biofuels would appear as groundless, except if focussed on R\&D actions and justified by research and testing.

Also, with respect to semantics, EBB is suggesting to the European Commission and to national authorities, if possible, not to refer in the official frame of the revised Directive to these new groups of biofuels technologies as well as to the currently available biofuels on the basis of a $1^{\text {st }}$ and $2^{\text {nd }}$ generation concept. Although some groups of mineral oil industry representatives, who for various reasons, including procrastination, seem to support mainly future biofuels, often refer to biofuels within such a "generational" frame, this definition appears to be misleading.

A generation often substitutes another who has become old and is ready to retire. Now currently available biofuels are not obsolete neither declining (a $65 \%$ increase in production only for biodiesel last year). Equally future biofuels technologies, although promising, have not yet entered in their "working age" and should not be seen as substitutes, but as complementary to biodiesel and bioethanol (also considering how ambitious the Directive targets are). Thus EBB would recommend the Commission to use, if possible, in the revised Directive the much more direct concepts of available biofuels and future biofuels (technologies) that would be much more appropriate than the "generational" misleading metaphor, this also in order to avoid any kind of negative competition between future and currently available biofuels.

\section{A positive effort towards biofuels R\&D based on present and future biofuels technologies}

Instead of a negative competition between available biofuels and future biofuels technologies it would be eventually wise to consider the important potential existing behind a thorough exploration of the concept of cogeneration of biofuels (e.g. a combined production of biodiesel, bioethanol and biomass-to-liquid) and the combination of their properties in order to create optimal fuels for future engine technologies.

Research and development should focus not only on future biofuels technologies but also on the improvement of the existing ones. There is a large potential for improving available biofuels production chain, acting on the research of new alternative, on higher quality raw materials (for biodiesel for instance on High Oleic Sunflower, other oilseeds crops, better recycling of UFO, animal fats, oil extraction from algae, etc.), on better outlets for the by-products (glycerine to be used as a biofuel itself as GTBE...) and on the industrial process itself. Dissemination activities are also strategically important ${ }^{4}$.

\section{Future EU biodiesel developments: will enough raw materials be available?}

The EU biofuels strategy needs to be consistent. The promotion of the use of biofuels cannot be dissociated from a proportional incentive given to the production of EU agricultural raw materials for biofuels.

As far biodiesel is concerned the production of non-food oilseeds is today encouraged via two main tools: the non-food set-aside scheme and the energy crop regime.

With respect to set-aside regime, we should consider that:

- oilseeds on non-food set-aside are limited by the Blair house limit of 1 billion tonnes soybean meal equivalent;

- such a limitation hampers the development of biofuels (it has not been increased after the accession of the new countries);

- the set-aside regime does not apply in the ten new Member States;

- the increasing need for new arable land also because of increased demand from biofuels.

As a consequence $E B B$ is suggesting to $E U$ authorities to explore the possibility of reforming the non-food set-aside regime, eventually merging it with the energy crop scheme in order to achieve larger surfaces and larger premium also in the 10 new Member States. These countries in fact, together with accession countries such as Romania have a very large and rather unexploited potential for the production of raw materials for biodiesel and biofuels.

Equally as far as the energy crops scheme is concerned it would be also important to:

- extend its application to the new EU Member States, where sofar such regime does not apply under the so-called simplified CAP scheme;

- increase the surfaces covered by the scheme which today are limited to 1,5 million hectares: this is clearly at variance with the objective of producing between 12 and 18 million tonnes of biodiesel (i.e. of vegetable oil the conversion being 1: 1) by 2010;

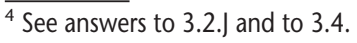

- increase the current premium of $45 € /$ ha (approximately $18 € /$ tonne) bringing it to a more substantial premium of $90 € /$ ha. The present premium in fact does not constitute a real incentive for those farmers and those countries that do not have an "energy crop" tradition, and there fore do not shift to such new concept of culture. A $90 € /$ ha would indeed create a different situation and push some farmers to change their cultural habits.

In this respect the European biodiesel industry fully backs the position and the scenarios that COPA-COGECA has realised about the need to further encourage the future production of agricultural raw materials for biodiesel.

\section{Biodiesel and straight vegetable oils use in the engines}

A specific consideration should also be added under this section of the Commission report about the use of Straight Vegetable Oils (SVOs) in diesel engines. Although the use of SVOs would require the engine to adapt to the fuel, its philosophy being different from biodiesel where the fuel adapts itself to the engine, many people, under the influence of misleading advertising or simply because SVO are sometimes fully exempted from the excise (like in Germany - where probably a problem of overcompensation already exists), ignore these recommendations and fuel their normal diesel engines with SVOs.

Unfortunately, normally an engine runs for a few thousand kilometres with SVOs, before stopping with serious damages to the injection system and to other internal engine parts. This has caused an impressive number of engine troubles and destructions in the last years, and has also had indirect negative impact on the biodiesel image (FAME comes from vegetable oils and sometimes the distinction between rape oil and rape esters is not really made by public opinion).

It would be important that the Commission assess the overall economical cost of such huge problems occurred in many EU members States starting from those countries were more important legislation in favour of biofuels have been adopted (Germany, France, etc.). On the basis of such evaluation it would be important to reconsider the cost-effectiveness of the option of including SVOs in the list of product for which a detaxation or an incentive should be provided; at least, if the detaxation of SVOs cannot be eliminated completely as EBB recommends, it should be made clear that SVOs use should be accompanied by a strong information campaign underlining that it is suitable only for fully adapted special Elsbett engines. 


\section{REFERENCES}

1. Document COM. 547 of $7 / 11 / 2001$.

2. AILEEN JAMIESON. Wood Mac Kenzie report. The long and short of it: European product imbalances and their implications. April. 2005.

3. COMMISSION STAFF WORKING DOCUMENT. page 9. SEC(2005) 1642 of 15.12.2005 Annex to the Report From The Commission Progress Towards Achieving The Community's Kyoto Target (required under Article 3(1) of Decision 280/2004/EC of the European Parlia- ment and of the Council concerning a mechanism for monitoring Community greenhouse gas emissions and for implementing the Kyoto Protocol) $\{\mathrm{COM}(2005) 655$ final $\}$.

4. PLOUCHART G. Évaluation des émissions de $\mathrm{CO} 2$ des filières énergétiques conventionnelles et non conventionnelles de production de carburants à partir de ressources fossils. Etude réalisée pour le Commissariat Cénéral au plan. IFP study. April. 2001.

5. ADEME-PWC. Energy and greenhouse gas balances of biofuels production chains in France. Dec. 2002.
6. Volkswirschafttliche Aspekte einer Herstellung von Biodiesel in Deutschland. IFO-Institut für Wirtshaftsforchung -2nd EU Motor Biofuels Forum/Sept 1996.

7. Eurobarometer June 2006 and EBB figures.

8. TAXUD DG. Tax reduction in favour of biofuels: the over-compensation issue. The cost for a family driving $20000 \mathrm{~km}$ per year, with an average consumption of 8 litres $/ 100 \mathrm{~km}$ would be 20-25 euros per year. Non Paper. March. 2004. 